\title{
Differences in mental health and health-related quality of life between the Israeli and Italian population during a COVID-19 quarantine
}

\author{
Anat Amit Aharon ${ }^{1}$ [ $\cdot$ Ilana Dubovi ${ }^{1} \cdot$ Angela Ruban $^{1}$ \\ Accepted: 23 December 2020 / Published online: 14 January 2021 \\ (c) The Author(s), under exclusive licence to Springer Nature Switzerland AG part of Springer Nature 2021
}

\begin{abstract}
Purpose Severe restrictions related to COVID-19 were implemented almost simultaneously in Italy and Israel in early March 2020, although the epidemic situation in both countries was significantly different. Therefore, the purpose of this study was to examine how and to what extent the severe restrictions affected the mental health and health-related quality of life of non-infected people, in a comparison between Israel and Italy.

Methods A cross-sectional study was conducted during the first week of May 2020 among 510 Israeli and 505 Italian participants. Anxiety and depression levels were measured using the Patient Health Questionnaire-4 (PHQ-4), and the short form-8 health survey (SF-8) questionnaire measured health-related quality of life. Linear hierarchic regression forced steps analysis was performed to measure the unique contribution of each variable to predicting health-related quality of life.

Results After adjusting for socioeconomic variables, the results showed a significantly higher anxiety level and lower healthrelated quality of life in the Italian participants. The anxiety and depression variables predicted lower health-related quality of life. Physical activity was found to be a protective factor.

Conclusion The results suggest that early monitoring of anxiety and depression in situations such as quarantine may detect the risk for decline in health-related quality of life. Establishment of professional interventions is needed in order to prevent the negative health consequences of the pandemic-related policy.
\end{abstract}

Keywords Depression · Anxiety $\cdot$ Health-related quality of life $\cdot$ COVID-19

\section{Introduction}

The 2019 outbreak of the coronavirus disease (COVID-19), caused by severe acute respiratory syndrome coronavirus 2 (SARS-Cov-2), emerged in Wuhan, China and spread to the entire country by the end of December 2019 [1]. In March 2020, the World Health Organization (WHO) declared COVID-19 a pandemic; it encouraged the world's population to collaborate and to radically change their lifestyle in order to fight the spread of the virus [2].

Supplementary Information The online version of this article (https://doi.org/10.1007/s11136-020-02746-5) contains supplementary material, which is available to authorized users.

Anat Amit Aharon

anatamit@tauex.tau.ac.il

1 Sackler Faculty of Medicine, Tel Aviv University, Tel Aviv, Israel
Italy, and the Lombardy region in particular, was severely affected by COVID-19 shortly after China was infected, making it the first European country to face a pandemic crisis [3-5]. On March 10, 2020, Lombardy was quarantined and the government instituted stronger containment measures, including strict self-isolation measures. [5-7] At that time, 3420 of Lombardy's 10,060,574 residents tested positive for COVID-19 [6]. Israel, on the other hand, is one of the countries that was initially affected by COVID-19 to a much lesser extent and that responded to the crisis relatively early. On March 17, 2020, the same restrictions were put into place by the Israeli government, although the number of positive patients at the time was 712 for a population of $9,136,000[8,9]$. Interestingly, both regions have a similar number of inhabitants and a similar geographical area. Both regions have characteristics of developed countries and a very intense and active social life. The two similar populations were put into lockdown facing a completely different reality outside the home. During this new pandemic, it is 
extremely important to better understand how the population has been coping with such a major disaster [10].

The psychosocial and health-related quality of life (HRQoL) response to an adverse event of this magnitude is complex; it involves considering many biological, psychological, social, and economic factors [11]. Different studies show that in an early phase of the severe acute respiratory syndrome (SARS) outbreak, a range of psychiatric morbidities may occurred, including depression, anxiety, panic attacks, and even suicide [10]. During the SARS outbreak, many studies investigated the psychological impact on the non-infected community, revealing significant psychiatric morbidities [12]. During one influenza outbreak, around $10 \%$ to $30 \%$ of the general public experienced severe stress [13]. With the closure of schools and businesses, negative emotions experienced by individuals are further compounded [14]. Strong fundamental evidence suggests that the reduction of social interactions is associated with higher depression symptoms and a higher risk of mortality [15]. Furthermore, some evidence suggests that the psychological impact of quarantine is wide ranging and long lasting [16]. Through this mechanism, the quarantine and social distancing related to COVID-19 has the potential of impacting the population's health-related quality of life. To date, only limited studies have investigated the severe impact of strict self-isolation on mental health and quality of life [11, 17].

Therefore, the aims of this study were to examine how the quarantine and social distancing during the COVID-19 pandemic affected the self-reported incidence of depression and anxiety and to evaluate its effect on HRQoL, among the adult population in Israel and Lombardy (Italy). Conducting the study in two similar populations to which the same restrictions were applied, though facing significantly different infection rates and mortality rates, provides a unique opportunity to perform comparative multivariate analysis and to identify major factors affecting public health.

\section{Materials and methods}

\section{Data source}

A cross-sectional study was carried out using the online internet polling service. The Israeli sample used the $i$-panel source, the largest panel survey in Israel, with more than 100,000 participants; the $i$-panel matched the population in Israel [18]. The i-panel adheres to the high-quality research code of the European Society for Opinion and Marketing Research (ESOMAR). The Italian sample used the CINT source. This is one of the largest panel surveys in Italy; the target area was Lombardy and quotas were used to match the composition of the local population. The Italian CINT adheres to the ESOMAR research code and was managed by an ASTRARICERCHE research company located in Milan. During the data collection, both Israel and Italy were in the end stage of the quarantine and had reopened local businesses with social distancing guidelines. Internet surveys such as $i$-panel and the CINT panel allowed the researchers to quickly collect data [19] while capturing similar end-stage quarantine circumstances in Israel and Italy. Brandon et al. reported that participants recruited to studies by internet panels generate data as valid as those provided by traditionally recruited participants [20].

The sample included adult participants from Israel and the Lombardy region in Italy. We used the G*Power program to calculate sample size for linear multiple regression [21], and considered a small effect size of $0.02, \alpha=0.05$, and a power of $80 \%$. Thus, the sample comprised 550 participants from each country. The final Israeli sample comprised 510 participants and the Italian sample comprised 505 participants (with $7.2 \%$ and $8.1 \%$ withdrawal, respectively). The questionnaire was distributed randomly via e-mail or a mobile phone application. The study used quota sampling to ensure the representative variables of gender, age, and SED status [22]. The study was conducted for one week beginning from May 7, 2020, two months after both countries were placed under lockdown.

\section{Measures of variables}

The study used three self-report questionnaires to measure anxiety and depression, HRQoL, and socioeconomic variables.

\section{Anxiety and depression}

Anxiety and depression were measured by the Patient Health Questionnaire-4 (PHQ-4) consisting of 4 items. The first 2 items assessed depression and the last 2 items anxiety. This tool was validated among the general population by Löwe et al. with an original Cronbach's alpha value of 0.78 for the depression scale and 0.75 for the anxiety scale [23]. The questionnaire is shown in Appendix 1 (Supplementary material). Replies were ranked on a scale ranging from 0 to 3 . The total score for the depression scale and for the anxiety scale was between 0 and 6 points each. A score of $\geq 3$ was suggested as a cut-off distinction point between a normal range and probably indicated initial symptoms of depression or anxiety. In the current study, the Cronbach's alpha values of the depression scales were 0.70 and 0.79 for the Israeli and Italian populations, respectively. The Cronbach's alpha values of the anxiety scales were 0.82 and 0.83 for the Israeli and Italian populations, respectively. 


\section{Health-related quality of life (HRQoL)}

HRQoL was measured by the short form- 8 health survey questionnaire (SF-8) tool. The SF-8 questionnaire is a shorter form of the SF-36 health survey tool. Both tools were found to be efficient and practical tools for assessing HRQoL [24]. The SF-8 is a short but comprehensive tool for measuring multiple dimensions of health status among various populations regardless of ages and health status. This tool assesses eight health concepts, including restrictions in various aspects of life due to physical, mental, emotional, and subjective health. The SF-8 included eight questions: one for each health domain. Four items assessed physical health, termed the physical component summary (PCS), and four items assessed mental health, termed the mental component summary (MCS) [25]. The SF-8 tool was validated in several studies, with good agreement of its internal consistency [26]. The current study found Cronbach's alpha values of 0.80 and 0.81 for the PCS among the Israeli and Italian groups, respectively, and 0.85 for the MCS for both the Israeli and Italian groups. The scoring method consisted of Norm-Based $T$-Scoring, which means that each item and the component summary have the same mean $(M=50)$ and standard deviation $(\mathrm{SD}=10)$, normalized to the general US population. This normalized scoring method allows comparison of the research sample with the reference population (US general population) [25]. The calibrated scoring was conducted under license number QM053998.

Both the SF-8 and the PHQ-4 questionnaires were translated into Hebrew and Italian and then back-translated into English [27].

\section{Socioeconomic variables}

Socioeconomic variables included gender, age, marital status, education (years), living with children, health status (options: yes/no chronic disease), owning an apartment, employment status before the COVID-19 outbreak, and employment status during the outbreak (options: as usual, part time, full time at home, part time at work, unpaid vacation, and layoff), average income before the COVID-19 outbreak, and status during the outbreak (options: no change; reduced; and sharply reduced), and physical exercise during the last 4 weeks (options: on a regular basis, sometimes, do not exercise).

\section{Data analysis}

Descriptive statistics were conducted to describe the research sample. Mean and SD were calculated for depression, anxiety, and the SF-8 questionnaires, comparing between the
Israeli and Italian samples. The differences between the Israeli and Italian samples were quantified using Cohen's $d$ effect size measure.

Linear multiple hierarchic regression forced steps analysis was performed to measure the unique contribution of each variable to predicting the dependent variable [28] in the PCS and the MCS. All the categorical variables were computed to a dummy variable, for example: "Israeli group $=0$ and Italian group $=1$ " or "no change in income status during the quarantine $=0$ and reduced income $=1$ ". Three steps were conducted: The first step included socioeconomic variables and health status. The second step included variables related to the COVID-19 quarantine: employment status, income level, and physical exercise. The third step included depression, anxiety, and groups (Israel/Italy). The explained variance $\left(R^{2}\right)$ and the statistically significant value of $F$ that changed were calculated for each of the models. The diagnostics parameter for multicollinearity was correlation, variance inflation factor (VIF), and tolerance. There was no correlation higher than 0.8 between the variables; the VIF range was $1.01-2.31$, and the tolerance range was $0.43-0.98$. This diagnosis suggests that each of the variables had a unique contribution to the dependent variable of PCS or MCS, with no multicollinearity interface [28]. Values of $p<0.05$ were considered significant. All analyses were performed using SPSS version 25.

The study was approved by the University Ethics Committee (number 0001366-1). The participants were asked to sign an informed consent form before beginning completion of the survey.

\section{Results}

Table 1 presents the samples' characteristics. The Israeli and Italian cohorts differed significantly in the following socioeconomic characteristics: age, owning an apartment/house, the number of children living at home, employment status, family income before and during the COVID-19 outbreak, and the level of physical exercise. In addition, the probability of the Italians having $a \geq 3$ score of anxiety (severe anxiety) was significantly higher than that of the Israelis $(50.2 \%$ vs. $42.2 \%, p=0.02$ ) (Table 2).

Table 3 presents the mean scores for depression, anxiety, the SF-8 health survey for each of the eight items separately, as well as PCS and MCS, in comparison between the Israeli and Italian cohorts. The anxiety level reported by the Israeli participants was significantly lower than that of their Italian counterparts $(M=0.97, \mathrm{SD}=0.86 ; M=1.17$, $\mathrm{SD}=0.86, p=0.0001$, respectively), with a moderate size effect $(d=-0.23)$. No significant differences in depression were found between the Israeli and Italian participants. In addition, the Israeli participants reported significantly 
Table 1 Sample characteristics: Israeli and Italian cohorts

\begin{tabular}{|c|c|c|c|c|c|}
\hline \multirow[t]{2}{*}{ Variable } & \multicolumn{2}{|c|}{ Israel $(n=510)$} & \multicolumn{2}{|c|}{ Italy $(n=505)$} & \multirow[t]{2}{*}{$P$} \\
\hline & $n(\%)$ & $M(\mathrm{SD})$ & $n(\%)$ & $M(\mathrm{SD})$ & \\
\hline Gender & & & & & 0.47 \\
\hline Male & $250(49.0)$ & & $259(51.3)$ & & \\
\hline Female & $260(51.0)$ & & $246(48.7)$ & & \\
\hline Age groups & & & & & 0.0001 \\
\hline $18-24$ & $91(17.8)$ & & $48(9.5)$ & & \\
\hline $25-34$ & $114(22.4)$ & & $79(15.6)$ & & \\
\hline $34-44$ & $103(20.2)$ & & $106(21.0)$ & & \\
\hline $45-54$ & $108(21.2)$ & & $124(24.6)$ & & \\
\hline $55-70$ & $94(18.4)$ & & $148(29.3)$ & & \\
\hline Marital status & & & & & 0.90 \\
\hline Married & $372(72.9)$ & & $370(73.3)$ & & \\
\hline Unmarried & $138(27.1)$ & & $135(26.7)$ & & \\
\hline Health status & & & & & 0.86 \\
\hline No chronic disease & $364(71.4)$ & & $363(71.9)$ & & \\
\hline With chronic disease & $146(28.6)$ & & $142(28.1)$ & & \\
\hline Owning an apartment/house & & & & & 0.001 \\
\hline Yes & $280(54.9)$ & & $336(66.5)$ & & \\
\hline No, rental & $127(24.9)$ & & $96(19.0)$ & & \\
\hline No, living with parents & $103(20.2)$ & & $73(14.5)$ & & \\
\hline Education (years) & & $14.03(2.52)$ & & $14.23(3.73)$ & 0.31 \\
\hline Number of children living at home & & $2.4(1.6)$ & & $1.3(0.9)$ & 0.0001 \\
\hline Employment status before COVID-19 & & & & & 0.0001 \\
\hline Unemployed & $63(12.4)$ & & $141(27.9)$ & & \\
\hline Public sector employment & $153(30.0)$ & & $64(12.7)$ & & \\
\hline Private sector employment & $214(42.0)$ & & $208(41.2)$ & & \\
\hline Self-employed & $29(5.7)$ & & $58(11.5)$ & & \\
\hline Student/Military service & $51(10.0)$ & & $34(6.7)$ & & \\
\hline Scope of employment before COVID-19* & & & & & 0.62 \\
\hline Full time & $312(78.8)$ & & $250(75.8)$ & & \\
\hline Part time & $56(14.1)$ & & $56(16.1)$ & & \\
\hline Per diem & $28(7.1)$ & & $27(8.2)$ & & \\
\hline Workplace before COVID-19* & & & & & 0.11 \\
\hline Outside home & $357(90.2)$ & & $283(85.8)$ & & \\
\hline At home & $11(2.8)$ & & $18(5.5)$ & & \\
\hline Both & $28(7.1)$ & & $29(8.8)$ & & \\
\hline Family income before COVID-19 & & & & & 0.0001 \\
\hline Below average & $277(54.3)$ & & $184(36.4)$ & & \\
\hline Average & 149 (29.2) & & $226(44.8)$ & & \\
\hline Above average & $84(16.5)$ & & $95(18.8)$ & & \\
\hline Employment during the COVID-19 quarantine* & & & & & 0.0001 \\
\hline As usual & $82(20.7)$ & & $53(16.1)$ & & \\
\hline Part time & $80(20.2)$ & & $49(14.8)$ & & \\
\hline Full time at home & $49(12.4)$ & & $79(23.9)$ & & \\
\hline Part time at work & $39(9.8)$ & & $43(13.0)$ & & \\
\hline Unpaid leave & $122(30.8)$ & & $74(22.4)$ & & \\
\hline Layoff & $24(6.1)$ & & $32(9.7)$ & & \\
\hline \multicolumn{6}{|l|}{ Income status during the COVID-19 quarantine } \\
\hline Unchanged & $169(33.1)$ & & $212(42.0)$ & & 0.004 \\
\hline
\end{tabular}


Table 1 (continued)

\begin{tabular}{|c|c|c|c|c|c|}
\hline \multirow[t]{2}{*}{ Variable } & \multicolumn{2}{|c|}{ Israel $(n=510)$} & \multicolumn{2}{|c|}{ Italy $(n=505)$} & \multirow[t]{2}{*}{$P$} \\
\hline & $n(\%)$ & $M(\mathrm{SD})$ & $n(\%)$ & $M(\mathrm{SD})$ & \\
\hline Reduced & \multicolumn{2}{|c|}{$228(44.7)$} & \multicolumn{2}{|c|}{$213(42.4)$} & \\
\hline Sharply reduced & \multicolumn{2}{|c|}{$113(22.2)$} & \multicolumn{2}{|c|}{$80(15.8)$} & \\
\hline \multicolumn{3}{|l|}{ Physical exercise during the past 4 weeks } & & & 0.01 \\
\hline As usual & \multicolumn{2}{|c|}{$113(22.2)$} & \multicolumn{2}{|c|}{$110(21.8)$} & \\
\hline Sometimes & \multicolumn{2}{|c|}{$245(48.0)$} & \multicolumn{2}{|c|}{$204(40.4)$} & \\
\hline Never & \multicolumn{2}{|c|}{$152(29.8)$} & \multicolumn{2}{|c|}{$191(37.8)$} & \\
\hline
\end{tabular}

The table shows the results of a Chi-square test for categorical variables and Mean (SD) for continuous variables. *Excluded: did not work; student; soldier

Table 2 The four-item patient health questionnaire (PHQ-4) for anxiety and depression, a comparison between Israeli $(n=510)$ and Italian participants $(n=505)$

\begin{tabular}{llll}
\hline Variable & $\begin{array}{l}\text { Israel }(n=510) \\
n(\%)\end{array}$ & $\begin{array}{l}\text { Italy }(n=505) \\
n(\%)\end{array}$ & $p$ \\
\hline $\begin{array}{l}\text { Depression score* } \\
\text { Score }<3\end{array}$ & $223(52.5)$ & $228(53.4)$ & 0.78 \\
Score $\geq 3$ & $202(47.5)$ & $199(46.6)$ & \\
Anxiety score* & & & 0.02 \\
Score $<3$ & $216(57.8)$ & $208(49.8)$ & \\
Score $\geq 3$ & $158(42.2)$ & $210(50.2)$ & \\
\hline
\end{tabular}

*Score $\geq 3$ indicates patients suspected of having depression/anxiety symptoms

higher PCS and MCS mean scores compared with the Italians (PCS: $M=52.47, \mathrm{SD}=7.88 ; M=50.35, \mathrm{SD}=7.90$, $p<0.0001$, MCS: $M=46.13 \mathrm{SD}=10.78 ; M=43.46$,
$\mathrm{SD}=10.03, p<0.0001$, respectively). The Cohen's $d$ value was 0.27 for the PCS difference and 0.26 for the MCS difference. These findings suggest that the HRQoL reported by the Israeli participants was higher than that of the Italian participants, and that it had a moderate sized effect. The correlation matrix of the variables can be seen in Appendix A1.

Table 4 presents a summary of hierarchical multiple linear regressions forced steps used to predict PCS and MCS among the Israeli and Italian cohorts. The table presents the final and third step of the regression, controlling for socioeconomic variables, health status, and quarantine-related variables (for example, employment during the quarantine).

PCS explanation (Table 4, model A): In the first step, the socioeconomic variables and health status were added. In step two, variables related to the quarantine, i.e., working, income status, and physical exercise, were added. In the final step, the depression, anxiety, and cohorts (Israel/ Italy) variables were added. After the socioeconomic,
Table 3 Comparisons between Israeli and Italian participants regarding depression, anxiety, PCS, and MCS levels (independent $t$-test and Cohen's $d$ for the effect size)

\begin{tabular}{lllccc}
\hline Variable & Israel & Italy & \multicolumn{2}{l}{$t$} & Cohen's $d^{\text {a }}$ \\
& $M(\mathrm{SD})$ & $M(\mathrm{SD})$ & & & \\
\hline Depression & $1.12(0.82)$ & $1.15(0.81)$ & 0.52 & -0.64 & -0.03 \\
Anxiety & $0.97(0.86)$ & $1.17(0.86)$ & 0.0001 & -3.73 & -0.23 \\
Health survey* & & & & & \\
General health & $51.72(7.14)$ & $47.18(7.38)$ & $<0.0001$ & 9.89 & 0.62 \\
Physical functioning & $50.10(7.00)$ & $48.12(5.75)$ & $<0.0001$ & 4.29 & 0.30 \\
Role-physical & $49.17(7.77)$ & $47.87(7.82)$ & 0.009 & 2.63 & 0.16 \\
Bodily pain & $53.43(7.61)$ & $53.38(7.40)$ & 0.91 & 0.11 & 0.00 \\
Vitality & $50.70(7.40)$ & $45.66(8.08)$ & $<0.0001$ & 10.29 & 0.65 \\
Social functioning & $47.22(9.36)$ & $46.97(8.29)$ & 0.66 & 0.44 & 0.02 \\
Role-emotional & $46.65(8.75)$ & $44.60(8.70)$ & $<0.0001$ & 3.70 & 0.23 \\
Mental health & $45.02(8.19)$ & $44.34(7.41)$ & 0.16 & 1.38 & 0.08 \\
PCS & $52.47(7.88)$ & $50.35(7.90)$ & $<0.0001$ & 4.26 & 0.27 \\
MCS & $46.13(10.78)$ & $43.46(10.03)$ & $<0.0001$ & 4.05 & 0.26 \\
\hline
\end{tabular}

*Health survey = eight items of the SF-8 health survey as tool used for measuring health-related quality of life PCS Physical Component summary, MCS mental component summary.

${ }^{\text {a }}$ Cohen's $d$ is the effect size of the differences 
Table 4 Summary of hierarchical regression analysis for variables predicting PCS and MCS among Israeli and Italian participants

\begin{tabular}{lll}
\hline Variable $^{\mathrm{a}}$ & PCS & MCS \\
& Model A & Model B \\
& B (CI) & B (CI) \\
\hline Gender & $0.23(-0.99$ to 1.46$)$ & $-0.48(-1.74$ to 0.77$)$ \\
Age & $-0.21(-2.63$ to 2.20$)$ & $-1.58(-4.06$ to 0.89$)$ \\
Marital status & $-1.85(-3.41 \text { to }-0.29)^{*}$ & $-0.40(-2.00$ to 1.19$)$ \\
Education & $0.19(0.001 \text { to } 0.38)^{*}$ & $-0.18(-0.37$ to 0.02$)$ \\
Owning an apartment & $0.13(-1.26$ to 1.76$)$ & $0.05(-1.38$ to 1.49$)$ \\
Living with children & $0.25(-1.26$ to 1.54$)$ & $0.15(-1.39$ to 1.70$)$ \\
Health status & $-6.12(-7.50 \text { to }-4.73)^{* * *}$ & $-2.17(-4.78 \text { to }-1.24)^{*}$ \\
Employment during the quarantine & $-0.36(-1.72$ to 0.99$)$ & $0.84(-0.55$ to 2.23$)$ \\
Income status during the quarantine & $0.16(-1.19$ to 1.52$)$ & $-0.82(-2.17$ to 0.57$)$ \\
Physical exercise during the quarantine & $1.44(0.004 \text { to } 2.88)^{*}$ & $2.68(1.20 \text { to } 4.16)^{* * *}$ \\
Depression & $0.09(-1.02$ to 1.21$)$ & $-4.56(-5.71 \text { to }-3.41)^{* * *}$ \\
Anxiety & $-4.19(-6.44 \text { to }-1.79)^{*}$ & $-6.33(-7.40 \text { to }-5.26)^{* * *}$ \\
Group: Israel/Italy & $-3.31(-4.58 \text { to }-2.04)^{* * *}$ & $-1.23(-2.51 \text { to }-0.09)^{*}$ \\
$R^{2}$ & 14.6 & 53.5 \\
$F$ change & $<0.0001$ & $<0.0001$ \\
\hline
\end{tabular}

The table presents the final and third step of the regression, controlling for socioeconomic variables, health status, and quarantine-related variables (for example, employment during the quarantine)

PCS Physical component summary, MCS mental component summary

${ }^{\text {a }}$ Category variables recoded to dummy variables, as described: Gender - male $=0$ and female $=1$; ageyoungest group 18 $-24=0$ and other groups -1 ; marital status - not married $=0$ and married $=1$; owning an apartment - no $=0$ and yes $=1$; health status - no chronic disease $=0$ and having a chronic disease $=1$; working during the quarantine - continued to work (as usual or part time) $=1$ and did not continue to work (unpaid vacation or layoff) $=0$; income status during the quarantine-no change $=0$ and reduced income $=1$; physical exercise-not exercising $=0$ and exercising as usual $=1$; group-Israel $=0$ and Italy $=1$

$* p<0.05 * * p<0.01 * * * p<0.001$ health status, and variables related to the quarantine were adjusted, the regression revealed that physical exercise $(B=1.44, p<0.05)$, anxiety level $(B=-4.19, p<0.05)$, and group $(B=-3.31, p<0.001)$ may explain the PCS. The $\mathrm{R}^{2}$ value was $14.6 \%$ and the model was significant $(p<0.0001)$. This finding suggests that not being physically active during the quarantine, a higher level of anxiety, and being Italian may explain the lower PCS.

MCS explanation (Table 4, model B): The variables were added to the regression as in model $\mathrm{A}$. In the final step, after the socioeconomic, health status, and variables related to the quarantine were adjusted, the regression revealed that physical exercise $(B=2.68$, $p<0.001)$, depression $(B=-4.56, p<0.001)$, anxiety level $(B=-6.33, p<0.001)$, and group $(B=-1.23$, $p<0.05)$ explained the MCS. The $\mathrm{R}^{2}$ value was $53.5 \%$ and the model was significant $(p<0.0001)$. These findings suggest that not being physically active during the quarantine, having a higher level of depression and anxiety, and being Italian explained the lower MCS.

\section{Discussion}

Unlike previous global disasters such as Ebola and SARS as well as the experience gained, the COVID-19 pandemic has a unique characteristic: strict social isolation and the restriction of movement for millions of people, with a few justified exceptions. This situation drastically changed the life of the population, which can have a potentially wide range of health impacts. The majority of the research conducted on COVID-19 relates to its clinical manifestations, how it is transmitted, the genomic characterization of the virus, and therapeutic options.

The current study aimed to explore the health consequences of quarantine and social distancing during the COVID-19 pandemic, focusing on depression, anxiety, and HRQoL in the Israeli versus the Italian community. These two developed countries with advanced health services and a similar national health service model [4] followed 
the same restrictions, but experienced the COVID-19 pandemic at different intensities.

Our results show higher levels of anxiety and depression during the COVID-19 pandemic in both samples compared to the reported prevalence in the general population in previous years. The data from the Italian National Statistical Institute indicate a severe anxiety prevalence of $4.2 \%$ and a depressive symptoms prevalence of $5.4 \%$ several years before the pandemic [29]. According to the Israeli Central Bureau of Statistics, in the last decade the prevalence of anxiety in Israel's general population was 3.6\% while the prevalence of depression was about 10.5-12\% [30]. In April 2020, one-third of the adult Israeli population reported feeling anxiety and depression [31]. In Italy, 29.7\% reported depression symptoms and $23.2 \%$ reported anxiety in a study conducted in the first 14 days of the quarantine [32]. This suggests that the depression and anxiety symptoms were worse both in the Israeli and in the Italian population during the quarantine. On the other hand, the level of HRQoL among the Israeli sample was similar to that found by Baron Epel et al. in Israel, as measured by the SF-12 instrument [33]. In the current study, the Italian participants had a higher level of anxiety symptoms and lower HRQoL (represented by PCS and MCS), compared with their Israeli counterparts. Similar results were reported among the general population during the COVID-19 quarantine in a study conducted in China, which reported higher prevalence of anxiety and depression during the lockdown: $35.1 \%$ prevalence of anxiety and $20 \%$ prevalence of depression symptoms [34].

At the time the current study was conducted, the number of positive COVID-19 cases in Lombardy was 82,028, which represents an infection rate of 8154 cases per one million citizens, with 14,294 deaths [35]. In contrast, the number of positive COVID-19 cases in Israel was 16,348, which represents an infection rate of 1793 cases per one million citizens, with 239 deaths [36]. The literature describes increases in anxiety disorders among people who are exposed to a disaster event [37, 38]. Similar findings were demonstrated among non-infected students regarding the COVID-19 pandemic [39] and the general population [40]. Previous outbreaks such as Ebola, swine flu, and MERS revealed that such disasters cause a deep and wide range of negative mental and health impacts [13, 14, 41]. Thus, the mere exposure to a larger number of COVID-19 cases and deaths led to an elevated level of stress and anxiety among the Italians. This may explain the higher level of anxiety among Italians compared with Israelis, since the severity and the period of restrictions were similar.

Moreover, previous studies found that exposure to natural disasters causes a drop in quality of life, and that the decrease in HRQoL may continue some years after the event [42]. Cui and Han reported that the perceived risk of disaster mediated the association between disaster and impaired quality of life [43]. If so, then the exposure to higher levels of COVID-19 as well as the higher death rates in Italy compared to Israel might have led to higher perceived risk, explaining the lower HRQoL among Italian participants. In addition, the current study found that having a chronic disease may predict lower HRQoL. This finding was consistent regardless of the variables of quarantine and social distancing related to COVID-19. These results support previous studies, which found a low HRQoL among chronically ill patients $[24,44]$. However, after adjusting for the health condition, physical exercise during the quarantine and social distancing, and the level of depression and anxiety explained the lower PCS and MCS. Surprisingly, none of the socioeconomic variables explained the HRQoL, except for marital status and only for PCS. Indeed, the correlation matrix found very low significant correlations (if any) between the groups and socioeconomic variables suggesting that the significance was found due to the large sample size [45].

The results of the current study reveal significantly higher HRQoL levels for the Israeli participants, in comparison to the Italian participants. Interestingly, HRQoL levels for both Israelis and Italians are as the average score with the reference population (US general population) in PCS but lower in MCS [25, 26], meaning that there was no dramatic decrease in HRQOL both for the Israeli and for the Italian sample. This can be explained by the fact that by the time of the study, when the quarantine policy was nearing its end, the public felt more optimistic about the near reopening, which in turn improved HRQoL, as optimistic perceptions and hope were found to be associated with improved HRQoL [46-48]. A longer quarantine may have had a higher impact manifested in a dramatic drop in HRQoL. This issue is beyond the scope of the current study. However, the findings of the current study provide evidence for the importance of early detection of signs of decline in HRQOL in order to prevent the dramatic decline in HRQoL over time as much as possible in circumstances of pandemic and quarantine, for the benefit of public health.

Notably, employment status and income status during the quarantine and social distancing do not predict HRQoL. In Italy, many small family businesses suffered due to the quarantine [5], with an $11.1 \%$ rate of unemployment [35]. In Israel, the unemployment rate reached as much as $20 \%$, with a $3 \%$ decrease in the standard of living [49]. Previous studies investigating unemployment and lack of income found long-term consequences for depression and quality of life [50, 51]. In the case of COVID-19, it was often clear that changes in employment status were temporary and that there was hope for a return to work. In some cases the state partially covered the unpaid leave, which has greatly eased the economic hardship [49].

Finally, being physically active during the quarantine is a protective factor for both PCS and MCS, corroborating 
previous studies that found that exercise is a protective factor for depression and HRQoL [52, 53]. This finding suggests that even in circumstances of pandemic-related quarantine, health policymakers should encourage the public to engage in physical activity as an indispensable tool for coping with the pandemic in order to promote mental and physical health.

This study has several limitations. It was an internetbased survey with volunteer participants who had a computer or smart mobile phone; this might impair the sample's representativeness. Although the literature indicates that an internet-based sample provides validated data [20], it may hamper possible generalization of the findings. In addition, this was a cross-sectional study with limitations in determining causal associations. Moreover, the basic data on depression, anxiety, and HRQoL were drawn from previous studies conducted among the general Israeli and Italian population. We recommend further longitudinal research in order to compare the results to our findings.

\section{Conclusions}

The current study was conducted among the general population in specific circumstances of a quarantine and social distancing during the COVID-19 pandemic. The main results of our study showed that anxiety and depression levels were higher during the COVID-19 pandemic in both Italy and Israel, but the anxiety level was significantly higher among Italians. Moreover, anxiety and depression were the main variables predicting HRQoL. These findings suggest that among the general non-infected population under quarantine and social distancing, anxiety and depression are potential health problems that lead to lower HRQoL. It is important that these findings on the health implications of quarantine and social distancing receive the attention needed among health policymakers. Anxiety and depression are initial signs that may predict a decline in physical and mental health.

We believe that there is an urgent need to deepen our knowledge about the mental and physical health of noninfected populations as a first step for developing effective, professional interventions, so that the negative health consequences of COVID-19 pandemic-related policy can be reduced. The WHO determined that HRQoL is an important health outcome [54]. Therefore, in the context of COVID19 , early monitoring of anxiety and depression may promote HRQoL for the long-term benefit of public health, help return the economy to its former strength, and improve citizens' lives.

A few months after the end of the study, Israel and a month later Italy were placed in a second lockdown, with the same severe restrictions as in the first round. However, one important exception was that the population in both countries was now allowed to engage in outdoor physical activities at any distance from their home. This governmental decision supported our research finding concerning the meaningful protective effect of physical activity for the mental health and quality of life of the general population.

Funding This research received no specific Grant from any funding agency in the public, commercial, or not-for-profit sectors.

\section{Compliance with ethical standards}

Conflict of interest The authors declare that they have no conflict of interest.

Ethical approval The study was approved by the University Ethics Committee (Number 0001366-1).

\section{References}

1. Zhu, N., Zhang, D., Wang, W., Li, X., Yang, B., Song, J., et al. (2020). A novel coronavirus from patients with pneumonia in China, 2019. The New England Journal of Medicine, 382(8), 727-733. https://doi.org/10.1056/NEJMoa2001017.

2. Betsch, C., Wieler, L. H., Habersaat, K., \& COSMO group. (2020). Monitoring behavioural insights related to COVID-19. The Lancet, 395(10232), 1255-1256. https://doi.org/10.1016/ S0140-6736(20)30729-7.

3. Porcheddu, R., Serra, C., Kelvin, D., Kelvin, N., \& Rubino, S. (2020). Similarity in case fatality rates (CFR) of COVID-19/ SARS-COV-2 in Italy and China. Journal of Infection in Developing Countries, 14(2), 125-128. https://doi.org/10.3855/jidc.12600

4. Remuzzi, A., \& Remuzzi, G. (2020). COVID-19 and Italy: What next? The Lancet, 395(10231), 1225-1228. https://doi. org/10.1016/S0140-6736(20)30627-9.

5. Lazzerini, M., \& Putoto, G. (2020). COVID-19 in Italy: Momentous decisions and many uncertainties. The Lancet. Global health, 8(5), e641-e642. https://doi.org/10.1016/S2214-109X(20)30110 -8 .

6. Grasselli, G., Pesenti, A., \& Cecconi, M. (2020). Critical care utilization for the COVID-19 Outbreak in Lombardy, Italy: Early experience and forecast during an emergency response. The Journal of the American Medical Association. https://doi.org/10.1001/ jama.2020.4031

7. Gatto, M., Bertuzzo, E., Mari, L., Miccoli, S., Carraro, L., Casagrandi, R., \& Rinaldo, A. (2020). Spread and dynamics of the COVID-19 epidemic in Italy: Effects of emergency containment measures. Proceedings of the National Academy of Sciences of the United States of America, 117(19), 10484-10491. https://doi. org/10.1073/pnas.2004978117.

8. WHO, W. H. O. (2020). Coronaviruse disease 2019 (COVID-19), situation report - 61 (No. 61). World Health Organization.

9. C B S. (2019). Statistic annual for Israel. centeral bureau statistics. Retrieved from https://www.cbs.gov.il/he/publications/Pages /2019/2019.aspx

10. Xiang, Y.-T., Yang, Y., Li, W., Zhang, L., Zhang, Q., Cheung, T., \& Ng, C. H. (2020). Timely mental health care for the 2019 novel coronavirus outbreak is urgently needed. The Lancet. Psychiatry, 7(3), 228-229. https://doi.org/10.1016/S2215-0366(20)30046-8. 
11. Zhang, Y., \& Ma, Z. F. (2020). Impact of the COVID-19 pandemic on mental health and quality of life among local residents in Liaoning Province, China: A cross-sectional study. International Journal of Environmental Research and Public Health. https:// doi.org/10.3390/ijerph17072381

12. Sim, K., Huak Chan, Y., Chong, P. N., Chua, H. C., \& Wen Soon, S. (2010). Psychosocial and coping responses within the community health care setting towards a national outbreak of an infectious disease. Journal of Psychosomatic Research, 68(2), 195-202. https://doi.org/10.1016/j.jpsychores.2009.04.004.

13. Rubin, G. R., Potts, H. W. W., \& Michie, S. (2010). The impact of communications about swine flu (influenza A H1N1v) on public responses to the outbreak: Results from 36 national telephone surveys in the UK. Health Technology Assessment, 14(34), 183-266.

14. Van Bortel, T., Basnayake, A., Wurie, F., Jambai, M., Koroma, A. S., Muana, A. T., et al. (2016). Psychosocial effects of an Ebola outbreak at individual, community and international levels. Bulletin of the World Health Organization, 94(3), 210-214. https:// doi.org/10.2471/BLT.15.158543.

15. House, J. S., Landis, K. R., \& Umberson, D. (1988). Social relationships and health. Science, 241(4865), 540-545. https://doi. org/10.1126/science.3399889.

16. Brooks, S. K., Webster, R. K., Smith, L. E., Woodland, L., Wessely, S., Greenberg, N., \& Rubin, G. J. (2020). The psychological impact of quarantine and how to reduce it: Rapid review of the evidence. The Lancet, 395(10227), 912-920. https://doi. org/10.1016/S0140-6736(20)30460-8.

17. Amerio, A., Bianchi, D., Santi, F., Costantini, L., Odone, A., Signorelli, C., et al. (2020). Covid-19 pandemic impact on mental health: A web-based cross-sectional survey on a sample of Italian general practitioners. Acta bio-medica : Atenei Parmensis, 91(2), 83-88. https://doi.org/10.23750/abm.v91i2.9619.

18. Bodas, M., \& Peleg, K. (2020). Self-isolation compliance in the COVID-19 era influenced by compensation: Findings from a recent survey in Israel. Health Affairs (Project Hope), 39(6), 936-941. https://doi.org/10.1377/hlthaff.2020.00382.

19. Miller, E. A., Berman, L., Atienza, A., Middleton, D., Iachan, R., Tortora, R., \& Boyle, J. (2017). A feasibility study on using an internet-panel survey to measure perceptions of E-cigarettes in 3 metropolitan areas, 2015. Public Health Reports, 132(3), 336-342. https://doi.org/10.1177/0033354917701888.

20. Brandon, D. M., Long, J. H., Loraas, T. M., Mueller-Phillips, J., \& Vansant, B. (2014). Online instrument delivery and participant recruitment services: Emerging opportunities for behavioral accounting research. Behavioral Research in Accounting, 26(1), 1-23. https://doi.org/10.2308/bria-50651.

21. Faul, F., Erdfelder, E., Lang, A.-G., \& Buchner, A. (2007). G*Power 3: A flexible statistical power analysis program for the social, behavioral, and biomedical sciences. Behavior Research Methods, 39(2), 175-191. https://doi.org/10.3758/BF03193146.

22. Im, E.-O., \& Chee, W. (2011). Quota sampling in internet research: Practical issues. Computers, Informatics, Nursing CIN, 29(7), 381-385. https://doi.org/10.1097/NCN.0b013e3181f9dc4 5.

23. Löwe, B., Wahl, I., Rose, M., Spitzer, C., Glaesmer, H., Wingenfeld, K., et al. (2010). A 4-item measure of depression and anxiety: Validation and standardization of the Patient Health Questionnaire-4 (PHQ-4) in the general population. Journal of Affective Disorders, 122(1-2), 86-95. https://doi.org/10.1016/j. jad.2009.06.019.

24. Lefante, J. J., Harmon, G. N., Ashby, K. M., Barnard, D., \& Webber, L. S. (2005). Use of the SF-8 to assess health-related quality of life for a chronically ill, low-income population participating in the Central Louisiana Medication Access Program (CMAP). Quality of Life Research, 14(3), 665-673. https://doi.org/10.1007/ s11136-004-0784-0.
25. Maruish, M. E., \& Turner-Bowker, D. M. (2009). A Guide to the development of certified modes of short form survey administration. QualityMetric Incorporated.

26. Ware, J. E., Kosinski, M., Dewey, J. E., \& Gandek, B. (2001). How to score and interpret single-item health status measures: A manual for users of the SF-8 health survey (p. 2001). Lincoln RI: QualityMetric Incorporated.

27. Brislin, R. W. (1980). Translation and content analysis of oral and written materials. Methodology, 2, 389-444.

28. Field, A. (2013). Discovering statistics using IBM SPSS statistics (4th ed.). London: SAGE Publications Ltd.

29. Mental health at various stages of life. (n.d.). Retrieved November 7, 2020, from https://www.istat.it/en/archivio/219812

30. Levinson, D. (2012). Anxiety and depression disorders in Israel: The World Mental Health Survey Initiative (Hebrew). Jerusalem: Ministery of Health.

31. Dovrin, N. (2020). Civil resilience during the Coronavirus crisis. Israel: Central Bureau of Statistics.

32. Gualano, M. R., Lo Moro, G., Voglino, G., Bert, F., \& Siliquini, R. (2020). Effects of Covid-19 lockdown on mental health and sleep disturbances in Italy. International Journal of Environmental Research and Public Health. https://doi.org/10.3390/ ijerph17134779.

33. Epel, O. B., Kaplan, G., \& Moran, M. (2010). Perceived discrimination and health-related quality of life among Arabs and Jews in Israel: A population-based survey. BMC Public Health, 10, 282. https://doi.org/10.1186/1471-2458-10-282.

34. Huang, Y., \& Zhao, N. (2020). Generalized anxiety disorder, depressive symptoms and sleep quality during COVID-19 outbreak in China: A web-based cross-sectional survey. Psychiatry Research, 288, 112954. https://doi.org/10.1016/j.psych res.2020.112954

35. Italy: Resident Population by Region 2019 | Statista. (n.d.). Retrieved June 23, 2020, from https://www.statista.com/stati stics/617497/resident-population-italy-by-region/

36. WHO. (2020). Coronavirus disease (COVID-19). Situation report-109 (No. 109). World Health Organization.

37. Goldmann, E., \& Galea, S. (2014). Mental health consequences of disasters. Annual Review of Public Health, 35(1), 169-183. https://doi.org/10.1146/annurev-publhealth-032013-182435.

38. Jones, J. H., \& Salathé, M. (2009). Early assessment of anxiety and behavioral response to novel swine-origin influenza A(H1N1). PLoS ONE, 4(12), e8032. https://doi.org/10.1371/ journal.pone.0008032.

39. Huckins, J. F., daSilva, A. W., Wang, W., Hedlund, E., Rogers, C., Nepal, S. K., et al. (2020). Mental health and behavior of college students during the early phases of the COVID-19 pandemic: Longitudinal smartphone and ecological momentary assessment study. Journal of Medical Internet Research, 22(6), e20185. https://doi.org/10.2196/20185.

40. van Agteren, J., Bartholomaeus, J., Fassnacht, D. B., Iasiello, M., Ali, K., Lo, L., \& Kyrios, M. (2020). Using internet-based psychological measurement to capture the deteriorating community mental health profile during COVID-19: Observational study. JMIR mental health, 7(6), e20696. https://doi. org/10.2196/20696.

41. Hall, R. C. W., Hall, R. C. W., \& Chapman, M. J. (2008). The 1995 Kikwit Ebola outbreak: Lessons hospitals and physicians can apply to future viral epidemics. General Hospital Psychiatry, 30(5), 446-452. https://doi.org/10.1016/j.genhosppsy ch.2008.05.003.

42. Wen, J., Shi, Y., Li, Y., Yuan, P., \& Wang, F. (2012). Quality of life, physical diseases, and psychological impairment among survivors 3 years after Wenchuan earthquake: A population based survey. PLOS ONE, 7(8), e43081. https://doi.org/10.1371/journ al.pone. 0043081 . 
43. Cui, K., \& Han, Z. (2019). Association between disaster experience and quality of life: The mediating role of disaster risk perception. Quality of Life Research, 28(2), 509-513. https://doi. org/10.1007/s11136-018-2011-4.

44. Turner-Bowker, D. M., Bayliss, M. S., Ware, J. E., \& Kosinski, M. (2003). Usefulness of the SF-8 Health Survey for comparing the impact of migraine and other conditions. Quality of Life Research, 12(8), 1003-1012. https://doi.org/10.1023/a:1026179517081.

45. Bujang, M. A., \& Baharum, N. (2016). Sample size guideline for correlation analysis. World Journal of Social Science Research, 3(1), 37. https://doi.org/10.22158/wjssr.v3n1p37.

46. Lucas, A. G., Chang, E. C., Morris, L. E., Angoff, H. D., Chang, O. D., Duong, A. H., et al. (2019). Relationship between hope and quality of life in primary care patients: Vitality as a mechanism. Social Work, 64(3), 233-241. https://doi.org/10.1093/sw/swz014.

47. Stevens, E., Guerrero, M., Green, A., \& Jason, L. A. (2018). Relationship of hope, sense of community, and quality of life. Journal of Community Psychology, 46(5), 567-574. https://doi. org/10.1002/jcop.21959.

48. de Rooij, B. H., Thong, M. S. Y., van Roij, J., Bonhof, C. S., Husson, O., \& Ezendam, N. P. M. (2018). Optimistic, realistic, and pessimistic illness perceptions; quality of life; and survival among 2457 cancer survivors: The population-based PROFILES registry. Cancer, 124(17), 3609-3617. https://doi.org/10.1002/cncr.31634

49. Endeweld, M., Heler, O., \& Karadi, L. (2020). The impact of the recession on thestandard of living, poverty and inequality -following the coronavirus (Working Pages No. 133). Jerusalem: National Insurance Insititute. Retrieved from http://www.btl.gov.il
50. Crowe, L., Butterworth, P., \& Leach, L. (2016). Financial hardship, mastery and social support: Explaining poor mental health amongst the inadequately employed using data from the HILDA survey. SSM Population Health, 2, 407-415. https://doi. org/10.1016/j.ssmph.2016.05.002.

51. Mousteri, V., Daly, M., \& Delaney, L. (2020). Underemployment and psychological distress: Propensity score and fixed effects estimates from two large UK samples. Social Science \& Medicine, 244, 112641. https://doi.org/10.1016/j.socscimed.2019.112641.

52. Nguyen, H. C., Nguyen, M. H., Do, B. N., Tran, C. Q., Nguyen, T. T. P., Pham, K. M., et al. (2020). People with suspected COVID19 symptoms were more likely depressed and had lower healthrelated quality of life: The potential benefit of health literacy. Journal of Clinical Medicine. https://doi.org/10.3390/jcm9040965

53. Ha, N. T., Duy, H. T., Le, N. H., Khanal, V., \& Moorin, R. (2014). Quality of life among people living with hypertension in a rural Vietnam community. BMC Public Health, 14, 833. https://doi. org/10.1186/1471-2458-14-833.

54. Escultura, Z. (Ed.). (2009). Milestones in health promotion statements from global conferences. Geneva: World Health Organization.

Publisher's Note Springer Nature remains neutral with regard to jurisdictional claims in published maps and institutional affiliations. 